\title{
Entrevista com John Urry
}

Interview with John Urry

\section{Concedida a Bianca Freire-Medeiros e Sérgio Carvalho Benício de Mello Lancaster, 8 de fevereiro de 2010}

Distinguished Professor da Universidade de Lancaster, John Urry é um dos maiores nomes da Sociologia contemporânea e tem contribuído com instigantes reflexões sobre globalização, turismo, consumo e, mais recentemente, mudanças climáticas. Ao longo de sua carreira, organizou 11 coletâneas e sete números especiais em periódicos de alta relevância, e publicou 74 artigos em revistas científicas e 100 capítulos de livros. Entre os 26 livros de sua autoria, o único traduzido para o português é $O$ olhar do turista (publicado originalmente em 1990 sob o título The Tourist Gaze), obra que inaugura em larga medida o campo da Sociologia do Turismo no Brasil.

Bianca Freire-Medeiros é pesquisadora do CPDOC/FGV e professora da Escola Superior de Ciências Sociais da FGV e do Programa de Pós-Graduação em História, Política e Bens Culturais do CPDOC, Rio de Janeiro, Brasil (bianca.freire.medeiros@fgv.br).

Sérgio Carvalho Benício de Mello é professor associado 2 do Programa de Pós-Graduação em Administração da Universidade Federal de Pernambuco (UFPE), Recife, Brasil (sergio.benicio@gmail.com). 
Desde o início dos anos 2000, John Urry vem se dedicando à consolidação do chamado paradigma das novas mobilidades, o qual propõe, em linhas gerais, uma teorização do "mundo social" como uma vasta coleção de práticas econômicas, sociais e políticas, bem como de infraestruturas e ideologias, que envolve, demanda ou (im)possibilita a movimentação de pessoas, objetos, informações e imagens. Subjacente a esse paradigma está a proposta de se abandonar a própria noção de sociedade como objeto da sociologia em favor do estudo pós-disciplinar das mobilidades em suas várias acepções. Tal proposta vem encontrando campo privilegiado de realização no Center for Mobilities Research (CeMoRe), centro de investigação fundado e coordenado pelo professor Urry pelo qual circulam pesquisadores de várias partes do mundo.

A presente entrevista foi realizada durante nossos estágios de pós-doutorado no Departamento de Sociologia de Lancaster e, como não poderia deixar de ser quando o interlocutor possui uma produção tão vasta, aborda temas variados: turismo, teoria sociológica clássica, cinema, mudança climática e as possibilidades e limites de uma "sociologia pós-carbono".

Como o senhor deve saber, $\mathrm{O}$ olhar do turista (na versão em português da primeira edição) ainda é, após tantos anos, o principal texto de referência da Sociologia do Turismo no Brasil. Apesar de focar em exemplos empiricos que se referem basicamente ao contexto britânico - como o senhor já reconheceu em outras ocasiões -, o livro fez sucesso no mundo inteiro e inspirou pesquisadores de contextos culturais diversos, como é comprovado pelo exemplo brasileiro. Isso é surpreendente, especialmente considerando o fato de que seu interesse pelo turismo como objeto de investigação foi, de certa forma, "acidental". Por que o senhor acha que o livro tem uma longevidade e um alcance tão notáveis?

- Bem, por várias razões. Em primeiro lugar, o título é bom. E o título é bom porque, de certa forma, resume os argumentos presentes no livro. Devo confessar que o título também foi acidental. Surgiu pouco antes de o livro ser enviado à editora. Eu estava tentando decifrar qual era de fato o argumento dele. Então, percebi que o livro era sobre o olhar do turista, então o título Teorizando o turismo, um título-padrão, foi alterado. Essa é uma das razões.

Em segundo lugar, e talvez o mais importante, não havia - bem, não tem havido, de certa forma, muita concorrência. Era um campo que estava emergindo, mas no qual não havia textos consagrados, com exceção do famoso livro de Dean McCannell, ${ }^{1}$ de 1976, que por volta de 1990 começou a ficar um pouco desatualizado. É um livro excelente, mas não teve muita pesquisa. Até certo ponto, embora tivesse muito a ver com o noroeste da Inglaterra, minha pesquisa trazia uma referência empírica, e provavelmente mostrou formas possíveis de realizar 
uma investigação, seja no campo da história social, da teoria cultural ou análises, do ponto de vista dos estudos culturais, de fenômenos específicos, seja no da cambiante economia política do turismo.

A mistura desses diferentes corpi de literatura voltou-se para um fenômeno com uma lente teórica particular, e isso aconteceu no início dos anos 1990, quando houve uma enorme proliferação de diferentes análises do consumismo, de objetos, mas também do consumismo do lugar, do consumismo através da multiplicação de diferentes tipos de signos, valores dos signos e assim por diante. O economista Joseph Stiglitz ${ }^{2}$ chamou os anos 1990 de "exuberantes", quando parecia que as fronteiras se desmanchavam por toda parte. O olhar do turista capturou uma parte dessa pulverização de fronteiras, ou seja, como as fronteiras estavam sendo transcendidas, nessa época, através dos múltiplos fluxos de pessoas, imagens dos lugares e assim por diante.

Na segunda edição, publicada em inglês em 2001, o senhor revitalizou o argumento, $e$ o livro assumiu uma perspectiva mais global. Atualmente, o senhor está trabalhando na terceira edição - O olhar do turista 3.0. Quais são os principais desafios e prazeres de rever suas próprias ideias duas décadas depois? E até que ponto essa nova edição se beneficiou do amadurecimento do paradigma das mobilidades? Confesso que gostei muito do título $\mathrm{O}$ olhar do turista 3.0.

- Isso me deixa muito satisfeito! O paradigma das mobilidades permite-me localizar tipos específicos de viagens de lazer num contexto muito mais amplo, no qual posso ver e examinar as formas pelas quais tipos de movimento muito diferentes são ou estão se tornando centrais em inúmeros aspectos da vida social e profissional. E também me possibilita, portanto, pensar em viagens de lazer não como algo restrito, específico, mas como algo muito mais generalizado, o que é muito útil. E, ainda, pensar nas diferentes formas e nos vários tipos diferentes de práticas sociais nos quais diferentes tipos de movimentos de lazer constituem padrões diversos de vida social.

Os desafios de escrever Oolhar do turista 3.0 são muitos. Em primeiro lugar, tenho de ser muito mais claro a respeito da relação entre a visualidade e os outros sentidos e deixar claro qual é a tese, o que não ficou tão claro nas duas primeiras edições. Dou, portanto, muito mais atenção aos múltiplos sentidos e às fugas sensoriais. Em segundo lugar, devo dar mais atenção também às formas em que as atuações múltiplas estão implicadas e envolvidas em diferentes tipos de viagem, de padrões de viagem. E, em terceiro lugar, tenho de levar em conta os custos de movimento, os custos que recaem sobre os indivíduos que viajam de avião o tempo todo, como em Amor sem escalas, ${ }^{3}$ aquele filme com George Clooney. Tenho ainda de ficar atento para os custos que incidem sobre os lugares, sobre o ambiente físico, como consequência de tal movimento. 
O livro traz um longo capítulo no final sobre os custos de viagem, que se referirá mais amplamente às questões relativas aos custos ambientais, mas também à possibilidade de que a extensão perpétua de viagens físicas alcance, em algum momento, algum tipo de limite físico. Embora o Brasil consiga superar isso temporariamente, através da suas imensas possibilidades de produção de biocombustível, isso certamente não é possível para todos os países do mundo. E se for verdade que as reservas de petróleo já chegaram ao seu limite, então existe a possibilidade de que este padrão de vidas móveis irá, mais cedo ou mais tarde, como dizemos em inglês, "invadir a zona de perigo", e isso pode provocar vários tipos de racionamento, por intermédio do controle de preços ou de outros meios. Na parte final desse novo livro, eu argumento justamente que o deslocamento físico não estará à disposição de muitas pessoas, em muitos países.

\section{O senhor decidiu reduzir ou suprimir alguma parte das duas edições anteriores?}

- Sim, alguns detalhes sobre o noroeste da Inglaterra. Uma parte dos dados é demasiadamente local e irrelevante. Uma parte do material sobre a organização do trabalho em serviços relacionados ao consumidor também está datada, e por isso vamos retirá-la ou atualizá-la. Alguns relatos de diferentes empresas envolvidas na indústria do turismo são muito específicos do Reino Unido e também estão datados e por isso também os suprimimos.

$O$ senhor disse algo sobre a extensão da paisagem ou lugares para onde ir. E as imagens? Não há mais "o que ver" nos lugares. Tudo pode ser visto do seu próprio escritório. O esgotamento das imagens também seria uma questão?

- Outro aspecto bastante explorado em 3.0 são os efeitos da Internet em geral e dos sites de rede social em particular, especialmente quando as pessoas criam narrativas de seus movimentos, que são postadas, e outras pessoas respondem a elas. De certa forma, viajar é, provavelmente, um dos elementos mais significativos das redes sociais. Esse é um aspecto. Em segundo lugar, como você disse, nós consideramos se, em algum momento, a proliferação de imagens chegará a um ponto em que poderá substituir o próprio ato de viajar. Há toda uma literatura que analisa se, em algum momento, haverá um efeito de substituição. Por enquanto, há indícios de que a proliferação de imagens produz e acompanha o desejo de ver com os próprios olhos.

\section{Estimulando mais turismo.}

Sim, mas será que a produção de imagens vai chegar a um estágio em que as imagens sejam tão boas quanto estar no lugar? Eu estava pensando sobre isso enquanto assistia ao filme Avatar em 3-D. Quando coloquei aqueles óculos, comecei imediatamente a pensar em imagens sendo criadas daquela forma, sem 
precisar, é claro, pôr aqueles óculos ridículos... Nesse caso, se tivéssemos imagens em 3-D que nos levassem ao Rio de Janeiro, por exemplo, as possibilidades seriam tantas, que isso poderia, numa escala significativa, passar a substituir a viagem corporal.

Mas, como o senhor disse antes, há tantos outros sentidos envolvidos...

- Com certeza. No livro, eu me refiro principalmente ao sentido de visão, mas também à audição. A qualidade do som de Avatar é impressionante. De qualquer forma, essas questões são discutidas nessa nova edição. É claro que isso também vai depender da ocorrência de uma mudança de grande magnitude no sistema daquilo que eu chamo de vidas móveis [mobile lives], que produza um "tratamento de choque" capaz de deixar as pessoas completamente temerosas de se movimentar fisicamente ou, então, completamente incapazes de fazê-lo.

... e que, ao mesmo tempo, fosse capaz de levá-las a lugares aonde não se poderia ir fisicamente. Por exemplo, já é possivel fazer o passeio completo da Cidade Proibida, em Pequim, em realidade virtual. É a única forma de ver o lugar inteiro, porque fisicamente certas áreas são restritas. Então, a realidade virtual passa a ser uma extensão da realidade.

- Se isso fosse feito em 3-D poderia ser bom, mas acho que o que teríamos de fazer, se fôssemos tentar projetar isso numa escala real, é nos afastarmos dela. Teria de ser um ambiente imersivo, o que é bem diferente.

É isso que a tecnologia promete, certo? Transportar as pessoas para dentro do filme.

- Com certeza. Mas ela é também, com toda certeza, uma grande consumidora de energia. Eu acho que Avatar é o filme mais caro de todos os tempos. O custo de carbono do filme foi enorme. Toda pesquisa feita no Google tem um custo de carbono, pois conta com servidores imensos que fazem uso de uma grande quantidade de eletricidade. Portanto, o virtual não está isento do custo carbono.

Essa perspectiva é muito interessante e nos leva a um tema-chave que gostaríamos de explorar mais a fundo. Refiro-me aos usos, às potencialidades e aos limites desse novo paradigma que o senhor vem desenvolvendo há bastante tempo e que expressou de forma inovadora no seu livro Mobilities (Mobilidades). 4 Para começar, gostaria de lhe perguntar até que ponto o paradigma das mobilidades é capaz de superar a dicotomia entre agência e estrutura, fundamental na tradição da Sociologia?

- Não gosto dessa distinção entre agência e estrutura por dois motivos. Primeiro, porque simplesmente reproduz a divisão entre os indivíduos e a sociedade, e eu não acho que essa divisão exista. Segundo, porque ignora aspectos do 
ambiente físico, tecnologias e aquilo que chamei vagamente de dispositivos móveis, incluindo todos os materiais, regras e textos que compõem possíveis dispositivos móveis. Por isso, acho que não vale a pena insistir nessa distinção e é com prazer que procuro superá-la. Suponho que caiba aos outros afirmarem se eu sou bem-sucedido ou não. Para mim, o crucial é que os sistemas, constituídos por séries de relações múltiplas, são sempre uma mescla do físico e do social, e das formas que eles são hibridizados. E os sistemas podem ser analisados através de algumas das ideias do pensamento complexo. Foi obviamente daí que tentei extrair o pensamento da teoria social, mas não uso os termos agência ou estrutura.

Em $\mathrm{O}$ olhar do turista, o senhor apresenta um interessantíssimo, e inesperado, uso de Foucault, especialmente os registros que ele fez de regimes modernos de visibilidade e vigilância. Em Mobilities, o senhor coloca em cena mais um autor que, normalmente, não é associado às questões que o senhor aborda. Estou falando de George Simmel, pensador social cuja contribuição tem sido marcada, em grande medida, pelo uso que a Escola de Chicago deu a ela. O senhor poderia elaborar, por favor, até que ponto "seu" Simmel é diferente, digamos, do Simmel de Robert Park?5

- Essa é uma pergunta difícil. O escritor que me inspirou foi Marshall Berman, com seu livro Tudo que é sólido desmancha no ar. ${ }^{6}$ Ele enxerga Simmel e, sem dúvida, Marx como analistas de um mundo moderno, móvel e fluido. Muitas pessoas foram cativadas por seu pensamento em relação à modernidade e com o pensamento ligeiramente mais específico a respeito de Simmel. Eu simplesmente examinei e reexaminei os aspectos mais urbanos e referentes a movimento, como os comentários de Simmel sobre o relógio de bolso e pontualidade. Após a leitura, parece óbvio, mas antes dessa leitura, eu nunca havia pensado sobre o tempo e a cidade de uma forma tão clara.

O senhor também usa a metáfora da ponte (de Simmel) e o faz de uma forma extremamente interessante.

- Sim. Eu sempre digo que Simmel foi o escritor que mais desenvolveu o pensamento sobre os padrões e consequências do movimento, do movimento na cidade, obviamente. E aquilo foi o primeiro sinal de um paradigma das mobilidades que foi interrompido. As pessoas não cruzaram a ponte. $\mathrm{O}$ uso muito específico que a Escola de Chicago fez de Simmel era muito mais sobre coisas relacionadas à organização, à estruturação e à padronização da vida urbana, traçando grandes contrastes entre esta e a vida rural. A noção de movimento como uma característica e propriedade mais geral se perdeu. Essas áreas extremamente especializadas da sociologia americana foram relativamente inúteis. 
Foi, portanto, a redescoberta de Simmel como um analista da modernidade nos anos 1990 - melhor dizendo, no final dos anos 1980 - que permitiu, mais uma vez, que várias pessoas, incluindo eu, o enxergassem como um pensador extremamente produtivo para essa guinada das mobilidades e, de um modo mais geral, para a natureza do pensamento social.

Uma questão central que, de uma forma ou de outra, tem sido encarada por todos os "pais" da Sociologia é ontológica: o que distingue a humanidade de outras criaturas que habitam a Terra? Marx, por exemplo, diria que é o trabalho, i.e., a capacidade dos homens e mulheres de mudar a natureza de uma forma criativa e produtiva. Seria correto afirmar que o senhor está sugerindo uma ontologia caracterizada não pelo trabalho ou pela linguagem (como seria apresentada pelos estruturalistas), mas pela capacidade humana de se movimentar com um propósito, de dominar a natureza através do movimento, de "mobilizar" o mundo físico?

- Essa pergunta é muito interessante. Não sei se a formularia de uma forma tão afirmativa, mas é isso, de certa forma, o que estou tentando dizer. Acho que você se referiu a algo que eu não havia expressado exatamente com essas palavras. Mas também vejo uma relação com Marx. Dá para perceber que sou influenciado por Marx, como resultado dos debates marxistas no campo da ciência social no Reino Unido e em outros lugares nos anos 1970 e1980. Mas você me fez pensar em algo que ele sempre diz a respeito do trabalho. Um elemento do trabalho é que ele geralmente pressupõe certas formas de "trabalhar" a natureza, e isso frequentemente envolve determinados tipos de movimento. Então, trabalho e movimento parecem estar entrelaçados de uma forma interessante.

O sistema da fábrica envolvia não apenas um grande número de pessoas que foram transportadas para um ambiente particular, mas, obviamente, a convergência de diferentes tipos de materiais, matérias-primas, habilidades e assim por diante, da transformação de matérias-primas que também tiveram de ser transportadas e colocadas em tipos de configurações novos e particulares. Há, pois, muitas formas em que o trabalho envolve múltiplos movimentos de pessoas e objetos, para explicar de uma forma bem simplista. É esse o conceito de metabolismo homem-natureza de Marx. Esse metabolismo é algo que ressurge através da organização de séries de movimento, múltiplas e sobrepostas. Enfim, concordo com o que você disse sobre a minha proposta, mas diria que ela também se relaciona com a proposta de Marx.

Bem, os dois, Marx e Simmel, afirmaram que a capacidade de transformar a natureza é peculiar aos seres humanos. Poderíamos dizer que o senhor está defendendo de forma mais enfática o papel do movimento nesse processo de transformação? 
- Sim, as formas múltiplas, diversas e sobrepostas de movimento. De fato, muitas coisas que são tidas como habilidades, ferramentas, instrumentos, equipamentos e assim por diante pressupõem o movimento de um indivíduo ou o movimento de um grande número de pessoas dentro ou através de diferentes tipos de ambientes. Isso tem relação com as questões em torno de visibilidade e vigilância, porque essas novas fábricas trouxeram novos tipos de sistemas de vigilância ou a crença de que as pessoas estavam dentro de um panóptico.

Em Sociology beyond Society (Sociologia para além das sociedades), ${ }^{7}$ o senhor argumenta que a "sociedade" sempre foi um conceito problemático, mas, mesmo assim, "o que une as pessoas?" é uma grande pergunta que continua atormentando os sociólogos. Com o advento da sociedade informática e tecnológica, em que redes inumanas desempenham um papel de destaque, como o senhor encararia essa pergunta?

- Obviamente, há muito tempo que a pergunta sobre o que é uma sociedade é importante. E, é claro, não deveríamos presumir que as sociedades contemporâneas sejam peculiares no que diz respeito à importância de redes inumanas: as sociedades do século XIX, com suas redes ferroviárias, as sociedades europeias do século XVIII, com seus canais, as sociedades do século XVI e XVII, com suas enormes redes mercantis atreladas à navegação. Quando fui ao Museu Viking, em Roskilde, na Dinamarca, deparei-me com um extenso relato de como os vikings desembarcaram praticamente em todos os países do mundo. Isso nos faz lembrar que redes inumanas são muito importantes em todas as sociedades, e nós não deveríamos imaginar que a nossa sociedade é diferente ou distinta de alguma forma.

Eu acho que o aspecto crucial das sociedades contemporâneas é que isso se tornou um fenômeno de massa, através de informações, conexões ou viagens físicas de lazer e assim por diante. Tornou-se um fenômeno de massa em vez de uma característica acentuadamente específica e localizada. Eu não tenho muito a dizer sobre isso, além do que todos dizem, mas há muitas formas em que padrões sociais são configurados, atualmente, à distância.

Os relacionamentos - profissionais, familiares ou de amizade - ocorrem através da presença imaginada dos outros. Os relacionamentos são uma mistura do co-presente com conexões em grande escala à distância. Portanto, quando falam sobre a sociedade, as pessoas estão se referindo a um conceito extremamente limitador. Ontem, eu estava numa reunião no Departamento de Transporte do Reino Unido, em Londres. Avalio a pesquisa e os procedimentos de pesquisa que eles fazem, e represento a "sociedade" nessas discussões. São pessoas do alto escalão que falam da sociedade como se a sociedade britânica fosse independente e auto-organizada, como se estivessem cercadas por barreiras. É incrível! E eles sa- 
bem da existência de tecnologias e sabem que as pessoas podem viajar para o continente, mas isso não é levado em consideração.

Pelo menos pensam diferentemente de Margaret Thatcher.

- Essa observação é muito boa. Eles estão convencidos de que a sociedade é extremamente importante, mas para eles, a globalização é algo inteiramente econômico, uma questão de grandes empresas que entram e saem do Reino Unido ou de qualquer outro lugar. Eu estava tentando falar sobre os fluxos de imagens, marcas e conexões produzidas por viagens internacionais e pela informação. Eles nunca haviam pensando sobre isso. A Sociologia, em seus aspectos globais e não econômicos, era algo que não estava presente, até então, nessas discussões.

Os nossos modos de "saber" estão sendo transformados por tecnologias "móveis"? A complexidade é a base do conhecimento "pós-social"?

- São duas perguntas, não? Em relação à pergunta sobre complexidade, acho que é uma forma de pensar muito interessante e produtiva. Nigel Thrift escreveu um belo artigo, publicado em 1999 em Theory, Culture Ev Society [Teoria, Cultura e Sociedade $],{ }^{8}$ sobre as ideias de complexidade como movimento, envolvendo movimento. Ele mostra como "noções complexas" entraram e saíram de todos os âmbitos de estudo, da física ao esoterismo, manuais de treinamento gerencial e assim por diante. Eu acho que seria possível fazer uma análise bem interessante dos movimentos que possibilitaram essa guinada da complexidade. Brian Arthur, por exemplo, é uma figura muito importante no que se refere a transportar ideias do pensamento complexo. Bem, essa é uma parte da sua pergunta.

A outra é muito mais ampla: como as nossas formas de saber estão sendo transformadas por tecnologias móveis? Mais uma vez, deveríamos ter cautela ao imaginar que as tecnologias móveis são uma novidade. Havia tecnologias móveis anteriores, como a impressão e o papel! Eu fui a um museu no País de Gales "anterior à impressão", que mostrava como era a vida antes da palavra escrita. Havia muitos livros no museu, livros escritos a mão. Mas os livros estavam acorrentados. Como aquelas eram as únicas cópias desses livros, não podiam ser levadas. Ficavam numa abadia que era uma biblioteca. $\mathrm{O}$ aspecto crucial dos livros é que eles estavam acorrentados. Eles eram absolutamente imóveis. A impressão permitiu que livros e papéis - aliás, a invenção do papel foi de grande impacto fossem reproduzidos e transportados.

Suponho que a ferrovia permitiu que isso acontecesse numa escala fantasticamente maior. As ferrovias facilitaram o desenvolvimento de jornais que podiam produzir notícias, notícias diárias, porque podiam ser transportados. Por isso, tenho sempre muita cautela em dizer que tudo é novo. Sempre há con- 
tinuidades interessantes. O que nós estamos usando? Nós estamos usando papel! Às vezes, gosto de pensar que se os computadores tivessem sido inventados primeiro, e depois alguém inventasse o papel, isso seria o "novo barato". Nós jogaríamos fora todos os nossos computadores idiotas! Há um belo livro chamado $O$ mito do escritório sem papel ${ }^{9}$ sobre a importância duradoura do papel, de como ele não caiu em desuso. Na verdade, o papel é uma tecnologia móvel muito útil.

Facques Derrida escreveu um livro chamado Papel-máquina, no qual teoriza sobre a máquina de escrever e o papel. O mundo é posto no papel e ele é uma espécie de tela primitiva, ou algo do tipo. É um livro muito bom... Eu concordo com tudo o que o senhor disse sobre a revolução do transporte e como a informação fluiu pelas ferrovias, mas isso levou tempo, foi algo muito lento comparado ao que temos hoje. Atualmente, estamos vivendo em tempo real, e essa é a questão - é possivel imaginar que os nossos modos de saber não estão sendo afetados por tecnologias em tempo real? Essa é minha pergunta. Como a epistemologia está se expandindo hoje em dia?

- Não sei. Não estou convencido de que haja tamanha variação. A área científica sobre a qual eu tenho lido um pouco, e que atualmente é muito importante, é a ciência climática, que inclui a formação do Painel Intergovernamental sobre Mudança do Clima (Intergovernmental Panel on Climate Change IPCC). ${ }^{10} \mathrm{~A}$ epistemologia climática é muito interessante e tem sido reformulada várias vezes através da comunicação em tempo real. A existência desta rede global extremamente poderosa chamada IPCC, uma combinação de cientistas e políticos reunidos para produzir uma caracterização particular das mudanças climáticas, permite a comunicação instantânea e muita troca de informações. E há reuniões globais altamente significativas, em que todos os tipos de pessoas se reúnem e buscam produzir um tipo de coalizão de interesses.

E um vocabulário comum.

- Sim, com certeza. Então, talvez o IPCC seja um bom exemplo para se estudar. Como não o estudei dessa forma, não tenho muito o que dizer além do que o Sérgio já disse. Produz-se um modo de saber, mas também de fazer, porque políticos e formuladores de políticas esperam que a ciência da mudança climática formule uma política instantaneamente, o que também é extremamente difícil e problemático. E, é claro, a ciência está altamente desigual e não há tempo suficiente para ela ser aplicada adequadamente e adquirir firmeza, antes que políticos e formuladores de políticas perguntem " $\mathrm{O}$ que faremos com relação ao problema de mudança climática?" ou "Será que esse problema de mudança climática não é aparente?" Talvez isso seja um bom exemplo do ponto de vista que você está tentando destacar. 
Num artigo recente, o senhor afirmou que "Não há uma sociedade global unificada, mas há níveis excepcionais de interdependência global". Entretanto, o senhor teoriza sobre relações sociais globais e um capitalismo global. Há um lugar que possa ser chamado de global?

- Bem, na verdade, eu estava pensando no filme Amor sem escalas e também no livro que editei com Saulo Cwerner e Sven Kesselring em Aeromobilities [Aeromobilidades]. ${ }^{11}$ Se há lugares que possam ser chamados de globais são esses corredores aéreos, mas por outro lado acho que o "global" não é uma coisa única, que está sendo construída, fabricada e executada. Eu nunca escrevi um livro, por exemplo, chamado "Sociologia global" ou "Sociedade global". Não usaria esses termos. Por que não dizer que há níveis excepcionais de interdependência global? Eu gostaria de enfatizar o movimento físico e os movimentos de imagens, informações, mensagens e assim por diante. Mas definitivamente não há uma sociedade global unificada. Quero deixar claro que isso é algo que ainda está em processo de formação $e$ que pressupõe grandes e crescentes reservas de energia. Estou obcecado com as bases energéticas da sociedade e acho que todas as Ciências Sociais, incluindo a Economia, têm sido extremamente ineficientes por não analisarem sistematicamente os recursos, especialmente os recursos energéticos, que sustentam as economias e as sociedades em geral, e a "global" em particular. Eu vejo essa formação do "global" como uma série de processos historicamente contingentes e possivelmente reversíveis.

O senhor está dizendo que essas condições mais físicas não foram dadas o devido valor?

- Eu acho Modernidade líquida, ${ }^{12}$ por exemplo, um ótimo livro! Foi lançado no mesmo ano que Sociology Beyond Societies, em 2000. Havia, obviamente, algo no ar que fez Zygmunt [Bauman] e eu (e outros, sem dúvida) pensar de forma parecida. Mas não há nada, até onde eu saiba ou lembre, sobre a importância dos recursos capazes de transformar tudo em líquido. Construir relacionamentos e transformar o mundo moderno em líquido é extremamente dispendioso, especialmente em termos de recursos energéticos. E, é claro, muitos recursos energéticos, com exceção do sol e, até certo ponto, das ondas e do vento, são finitos. De certa forma, isso é extraordinário e é por isso que algumas pessoas afirmam que estamos começando um novo período geológico, chamado de "antropoceno", inteiramente distinto e completamente diferente dos períodos anteriores, devido à forma pela qual vastos recursos, principalmente as reservas de carbono, têm sido mobilizados, literalmente mobilizadas, e usados para mobilizar pessoas, objetos, alimentos e água numa escala inacreditavelmente distinta. Acho que é isso que eu vejo como realmente diferente nisso tudo, mas isso tem 
sido um longo processo, iniciado, na realidade, em Lancashire, no final do século XVIII!

Uma enorme bacia de petróleo foi descoberta no Brasil, mas essa descoberta não terá vindo tarde demais?

- Bem, o problema é que, porque o petróleo é um recurso finito, é preciso continuar descobrindo campos de petróleo a uma velocidade muito acelerada, numa velocidade cada vez mais acelerada porque houve um enorme aumento, de dez a 15 vezes, no consumo de petróleo desde a década de 1960. Por isso, é preciso continuar descobrindo campos de petróleo numa velocidade cada vez mais rápida para gerar petróleo suficiente, a menos que o Brasil e os Estados Unidos tornem-se países produtores de biocombustíveis. Mas isso é inconcebível. O problema é que o auge da descoberta de petróleo foi na década de 1960 e, desde então, não foram descobertos campos de petróleo suficientes, em escala mundial, para acompanhar a demanda constante, e muito menos a demanda crescente, em grande escala.

Provavelmente vamos partir para outro tipo de produção de energia em vez de petróleo. Embora ainda haja petróleo para explorar, eu vejo uma mudança mais à frente.

- Sim. Atualmente, mais de $95 \%$ de toda a energia para transporte é baseada no petróleo. Mesmo com uma modesta quantidade de biocombustível, não há um plano B.

O senhor inicia seu livro Mobilities descrevendo como nós vivemos num mundo móvel e tecnológico cheio de oportunidades, e o senhor pergunta por que as pessoas ainda viajam fisicamente, quais são os usos, prazeres e dissabores, e que ramificações sociais e físicas tal movimento possui. Não deveríamos estar perguntando o que possibilita as pessoas se movimentarem? Essas tecnologias móveis são libertadoras e democráticas?

- Eu concordo que deveríamos estar fazendo essas perguntas. Libertadoras e democráticas? Elas parecem ser sempre uma mistura de libertação e vigilância. Muitas dessas tecnologias móveis estão implicadas em novas formas de monitoramento e vigilância, por isso sempre enxergo o lado negro delas. O otimismo inicial em torno da Internet - novas tecnologias iam produzir novos tipos de práticas democráticas ao redor do mundo-mostrou ser um equívoco. Embora novas formas de política tenham se formado, elas têm sido usadas tanto por forças antidemocráticas quanto pró-democráticas. Elas possibilitam novas formas de organização. Em geral, eu acho que se não houvesse custos de movimento, seria melhor as pessoas poderem se movimentar, ao invés de ficarem presas 
num lugar. Encontrar outras pessoas geralmente é uma coisa boa, mas que traz consequências e custos enormes... A população mundial é muito grande para isso acontecer. Se nós dissermos, literalmente, que 6,7 bilhões de pessoas têm o direito e deveriam ter os recursos para fazer três viagens longas ao ano, ou algo do gênero, isso seria um tremendo problema...

Na verdade, eu estava pensando em como uma pessoa deficiente era, até certo ponto, imóvel. Elas não podiam ir a muitos lugares. Agora, temos diferentes tipos de deficiência. Não só a deficiência física, mas também a tecnológica. Nem todas as pessoas têm os mesmos recursos altamente influenciados pela informação e pela educação que nós vemos espalhados pelo mundo inteiro. Então, isso vai continuar a gerar diferentes tipos de riqueza. A desigualdade entre os ricos e os pobres pode ser reinterpretada como aquela entre os ricos móveis e os imóveis - os pobres do futuro. $O$ senhor não acha interessante como o capital de rede não corresponde necessariamente ao capital econômico?

- Sim, com certeza. Bem, eu tento formular isso através do conceito de "capital de rede" e argumentando que o capital de rede é uma das principais bases de desigualdade social no mundo contemporâneo, que a escala e as desigualdades do capital de rede se tornaram mais pronunciadas, que é um capital, de certa forma, separado da renda ou do capital cultural. $E$ que a proliferação de formas aceleradas de movimento de ideias e, particularmente, o movimento de pessoas, aumentam essas desigualdades.

Essas desigualdades de capital de rede são bem menores quando, por exemplo, todos andavam, porque todos andam mais ou menos no mesmo ritmo. Algumas pessoas andam um pouco mais rápido, mas esse é um grau muito menor de desigualdade. Eu não pesquisei isso de verdade, e seria bom se outras pessoas pudessem estabelecer isso um pouco mais sistematicamente.

Seu estilo de escrever é, ao mesmo tempo, acessivel e provocativo, e o senhor tem talento para criar metáforas evocativas. Eu gostaria de relembrar uma dessas metáforas intelectualmente estimulantes que acho particularmente feliz: "o carro é a jaula de ferro da modernidade". O senhor poderia elaborar isso um pouco mais em relação à sua perspectiva dos cenários futuros?

- É claro! A jaula de ferro vem de Max Weber e de sua jaula de ferro da burocracia. Foi uma espécie de brincadeira com Weber, mas serviu para mostrar que, de modo geral, os aspectos cruciais da modernidade parecem ser, ou deveriam ser, sobre movimento. Embora Weber não possa ser culpado por ignorar o carro, a ciência social do século XX pode ser culpada por não lhe dar a devida atenção. $\mathrm{O}$ carro é uma característica significativa e difundida - ou, talvez, a característica mais significativa e difundida - do mundo moderno. O carro e todas 
as suas interconexões com o petróleo, com desenho urbano, com padrões e práticas de lazer, com cultura, literatura, questões envolvendo arte e design...

Individualismo e liberdade.

- Liberdade, isso mesmo, e obviamente filmes de estrada [road movies], música e assim por diante. É onde eu queria chegar e, de fato, no livro After the Car (Após o carro) (Polity 2009, com Kinsgley Dennis) há um capítulo em que tento elaborar isso. O carro é a jaula de ferro, é claro, e é também uma jaula muito interessante, porque ao mesmo tempo que é muito segura, percorre igualmente os campos de morte do ambiente urbano moderno. Mais de um milhão de pessoas são mortas por ano devido ao carro, embora muitas delas morram, certamente, ao se chocarem contra outras jaulas de ferro. Então, essa jaula de ferro é paradoxal. É uma espécie de proteção, uma espécie de casulo, mas também permite que as pessoas transitem por locais perigosíssimos, de certo modo, os locais de maior perigo. É ótimo porque transporta as pessoas, mas as transporta através de ambientes perigosíssimos. Desde a Segunda Guerra Mundial, foram mortas mais pessoas em estradas do que em guerras. E muito mais pessoas foram como ferimentos duradouros e potencialmente fatais que reduzem a qualidade de vida das pessoas.

Então, em relação a cenários futuros, o senhor acha que haverá um mundo sem carros?

- Eu acho que há vários cenários diferentes e que nenhum deles é altamente provável. Há várias possibilidades. Seria preciso analisar esses cenários diferentes para prever quais seriam as séries de eventos e processos que teriam de acontecer para um cenário particular se concretizar. Acho que provavelmente haverá, na maioria dos cenários, algumas formas duradouras de transporte pessoal. Não acho que o carro será substituído pelo transporte público. Isso deveria acontecer, mas eu não acho que vá acontecer.

O senhor editou uma edição especial da revista Theory, Culture \& Society sobre mudanças climáticas ${ }^{13}$ e está publicando um livoro intitulado Climate Change and Society ${ }^{14}$ (Mudança climática e sociedade). Qual é a centralidade da discussão sobre mudança climática no seu trabalho atual, e como o paradigma das mobilidades pode contribuir para esse debate altamente explosivo no campo político?

-É bastante significativo. O livro sobre mudança climática é uma tentativa de aproximar a sociedade das questões da mudança climática, mostrando que essa é uma questão social e tem a ver com atividades humanas. Mas que também é uma tentativa de deslocar a importância da economia da sua posição, em boa parte dominante, na reflexão sobre atividades humanas em relação à mudan- 
ça climática. Então, trata-se também de um livro antieconomia. Eu acho que o paradigma das mobilidades me ajuda a compreender um pouco disso, mas não acho que seja absolutamente central.

Gostaríamos de concluir esta conversa mencionando um episódio recente que nos leva a pensar sobre a complexa relação entre mobilidades e imobilidades, mudança climática e desastres climáticos, globalização e dependência econômica, turismo e fluxos migratórios. Como o senhor deve saber, uma chuva torrencial, seguida por deslizamentos fatais, destruiu ligações rodoviárias e ferroviárias em Machu Picchu, um dos destinos mais populares do Peru e da América Latina. Cerca de 3.500 turistas ficaram presos no local durante dias, até que finalmente puderam ser transportados por via área. Por causa desse desastre, acredita-se que Machu Picchu terá de permanecer fechada por até dois meses, um problema grave para uma nação como o Peru, cuja economia é altamente dependente do turismo. Enquanto o governo enviava, a pedido dos turistas, US\$400.000 para reabastecer caixas de autoatendimento vazios, aldeões locais começavam a migrar para cidades vizinhas, a procura de emprego. Como o paradigma das mobilidades poderia nos ajudar a compreender tudo isso?

- Acho fascinante o que você disse sobre Machu Picchu, e acho também que você fez uma boa análise. Concordo contigo e não tenho nada a acrescentar, além de apontar a importância dessas imobilizações temporárias dos fluxos de visitantes, o que parece acontecer cada vez mais na nova (des)ordem mundial. É uma imagem cada vez mais comum, nas mídias novas e antigas, turistas vestidos inapropriadamente e imobilizados com suas pilhas de malas, presos em pontos de encontros globais, como hotéis ou aeroportos, e buscando, desesperadamente, uma salvação, uma rota de saída daquele paraíso ensolarado. ${ }^{15}$

Muito obrigado, professor.

Notas

1. Maccannell, Dean. The Tourist: A New Theory of the Leisure Class. Nova York: Schocken Books, 1976.
2. Stiglitz, Joseph. Os exuberantes anos 1990. São Paulo: Companhia das Letras, 2003. 
3. Amor sem escalas (Up in the Air). [Filmevídeo] Direção de Jason Reitman. EUA, 2009, $109 \mathrm{~min}$.

4. Urry, John. Mobilities. Oxford: Polity Press, 2007.

5. Park, Robert. The city as a social laboratory. In: Smith, T. \& Whyte, L. (orgs.). Chicago: an experiment in social science research. Chicago: The University of Chicago Press, 1929, p. 1-19.

6. Berman, Marshall.Tudo que é sólido desmancha no ar: a aventura da modernidade. São Paulo: Companhia das Letras, 1986.

7. Urry, John. Sociology Beyond Society. Londres: Routledge, 2000.

8. Thrift, Nigel. "The Place of Complexity". Theory, Culture E Society, v. 16, n. 3, p. 310-70, 1999.
9. Sellen, Abigail \& Harper, Richard. The Myth of the Paperless Office. Cambridge: The MIT Press, 2001.

10. http://www.ipcc.ch/

11. Cwerner, Saulo; Kesselring, Sven; Urry, John. Aeromobilities: Theory and Method. Londres: Routledge, 2009.

12. Bauman, Zygmunt. Modernidade líqui$d a$. Rio de Janeiro: Jorge Zahar, 2001.

13. Szerszynski, Bronislaw \& Urry, John. Changing Climates: Introduction. Theory, Culture E Society, v. 27, n. 2, p. 1-8, 2010.

14. Urry, John. Climate Change and Society. Cambridge: Polity, 2011.

15. Ver, a esse respeito, Birtchnell, Thomas \& Büscher, Monika. "Stranded: An Eruption of Disruption". Mobilities (edição especial), v. 6 , n. 1, fev. 2011, p. 1-9. 